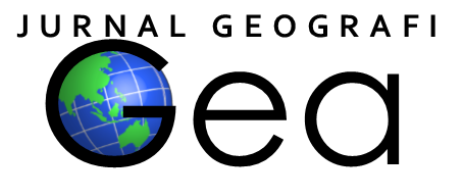

\title{
KONSERVASI JENIS LAMUN DI KAWASAN PERAIRAN PULAU PRAMUKA, KEPULAUAN SERIBU, PROVINSI DKI JAKARTA
}

\author{
Haviarini, C. $\mathbf{P}^{\mathbf{1}}$., Azahra,F. A ${ }^{\mathbf{2}}$, B, Refaldi ${ }^{3}$, Sofyan,O. $\mathbf{H}^{\mathbf{4}}$. \\ ${ }^{1,2,3,4}$ Prodi Pendidikan Geografi, Universitas Negeri Jakarta \\ Jl. Rawamangun Muka, Jakarta Timur, Indonesia \\ ${ }^{1}$ cynthiahavia@gmail.com,3baihaqialdi0@gmail.com,2fildzahalifah.faa@gmail.com
}

\begin{abstract}
Seagrass is one of the plants that support life in the sea, especially in coastal areas. Many benefits are generated from the existence of seagrass ecosystems or seagrasses for both ecosystems and biota in the sea and for economic and social conditions for local communities. This study aims to describe the types, characteristics and benefits of seagrass in the Thousand Islands National Park Region, especially on Pramuka Island, DKI Jakarta Province. The method used is seagrass data in the form of seagrass types and their characteristics. In addition, there were free interviews with officers from the Thousand Islands National Park (TNKpS) and through documents obtained through tracing using the keyword distribution of seagrasses, seagrass species through the internet. Data analysis was descriptive analysis to explain the types and characteristics of seagrasses and their conservation status. The results obtained were 7 types of seagrass, namely Cymodocea rotundata, Cymodocea serrulata, Enhalus acoroides, Halodule uninervis, Halophila ovalis, Thalassia hemprichii and Syringodium isoetifolium. seagrass benefits for coastal areas and the consequences of human activities in the area around the coast that also affect the condition of the seagrass community.
\end{abstract}

Keywords: Seagrass Conservation, Pramuka Island, Seagrass

\begin{abstract}
ABSTRAK
Lamun merupakan salah satu tumbuhan penyokong kehidupan dilaut, khususnya daerah pesisir. Banyak manfaat yang dihasilkan dari adanya ekosistem lamun atau seagrass baik untuk ekosistem dan biota di laut maupun bagi ekonomi dan sosial bagi masyarakat lokal. Penelitian ini bertujuan untuk mendiskripsikan jenis- jenis, ciri-ciri dan manfaat lamun yang ada di Kawasan Taman Nasional Kepulauan Seribu, khususnya di Pulau Pramuka, Provinsi DKI Jakarta. Metode yang digunakan adalah data lamun berupa jenis-jenis lamun dan ciri-cirinya. selain itu, ada wawancara bebas dengan petugas dari Taman Nasional Kepulauan Seribu (TNKpS) dan melalui dokumen yang diperoleh melalui penelusuran dengan menggunakan kata kunci distribusi lamun, spesies lamun melalui internet. Analisis data berupa deskriptif analisis untuk memaparkan mengenai jenis dan ciri lamun serta status konservasinya. Hasil yang didapatkan terdapat 7 jenis lamun yaitu Cymodocea rotundata, Cymodocea serrulata, Enhalus acoroides, Halodule uninervis, Halophila ovalis, Thalassia hemprichii dan Syringodium isoetifolium. Manfaat lamun bagi daerah pesisir dan akibat yang ditimbulkan dari aktivitas manusia di daerah sekitar pesisir yang juga mempengaruhi kondisi komunitas lamun.
\end{abstract}

Kata kunci: Konservasi Lamun, Pulau Pramuka, Seagrass 


\section{PENDAHULUAN}

Lamun atau Seagrass atau orang lokal kepulauan seribu menyebutnya samo-samo, rumput pama atau oseng merupakan tumbuhan tingkat tinggi (Antophyta) yang hidup dan tumbuh di lingkungan laut. Memiliki ciri berpembuluh, berdaun, berimpang (Rhizome), berakar dan berkembang biak secara generatif (biji) dan vegetatif (tunas). Rimpangnya merupakan batang yang beruas-ruas yang tumbuh terbenam dan menjalar dalam substrat pasir, lumpur dan pecahan karang.

Di Indonesia sendiri terdapat 15 jenis lamun yang dapat dijumpaiyaitu Enhalus acoroides, Cymodocea rotundata, Cymodocea serrulata, Halophila decipiens, Halophila ovalis, Halophila minor, Halophila spinulosa, Haludole pinifolia, Halodule uninervis, Syringodium isoetifolium, Thalassia hemprichii, Thalassodendron ciliatum Halophila sulawesii, Halophila becarii dan Ruppia maritima.

Di kawasan Taman Nasional Kepulauan Seribu atau TNKpS terdapat 7 jenis lamun yaitu,Enhalus acoroides, Thalassia hemprichii, Cymodocea serrulata, Cymodocearotundata, Halophila ovalis, Syringodium isoetifolium, dan Halodule uninervis (BTNKpS 2008).Padang lamun yang tercipta di hamparan pesisir memiliki banyak manfaat yaitu, sebagai produsen primer, habitat biota laut, stabilisator dasar perairan, penangkap sedimen dan pendaur hara.Di Indonesia, kondisi padang lamun telah dikategorikan dalam Keputusan Menteri Lingkungan Hidup nomor 200 tahun 2004.

Dalam Kepmen tersebut, kondisi padang lamun terbagi menjadi 3 kategori, yaitu sehat, kurang sehat dan miskin. Kategori sehat jika penutupan lamun di suatu daerah > 60\%, kurang sehat jika 30-59,9\% dan tidak sehat jika pentupan antara 0-29,9\%.Namun, seiring berjalannya waktu kondisi lamun kian menurun dan diduga akibat dari aktifitas manusia di wilayah sekitar pesisir Pulau Pramuka.

Tujuan dari penelitian ini adalah untuk mengetahui jenis-jenis lamun yang ditemui di wilayah TNKpS khusus nya Pulau Pramuka, serta pengaruh dari aktivitas masyarakat sekitar terhadap ekosistem lamun.

\section{METODE PENELITIAN}

Metode yang digunakan dalam penelitian ini adalah metode deskriptif analitik dan metode observasi. Metode Deskriptif Analitik adalah suatu metode yang berfungsi untuk mendeskripsikanatau memberi gambaran terhadap objek yang diteliti melalui data atau sampel yangtelah terkumpul sebagaimana adanya tanpa melakukan analisis dan membuat kesimpulan yang berlaku untuk umum (Sugiono, 2009:29) dan Metode observasi yang dilakukan dengan cara mengamati dan mencatat secara sistematik gejala-gejala yang diselidiki (Supardi, 2006:88).

Penelitian dilakukan di dua lokasi utama yaitu di Pulau Pramuka, Kepulauan Seribu Provinsi DKI Jakarta dan dilakukan pada tanggal 7 - 9 Desember 2018. Pengamatan mengenai jenis lamun dilakukan di Pulau Pramuka, Kepulauan Seribu.

Teknik pengumpulan data yang digunakan adalah data primer yang digunakan yaitu data yang diperoleh dari data kualitas perairan dan data lamun berupa jenis-jenis lamun dan ciri-cirinya. selain itu, ada wawancara bebas dengan petugas dari Taman Nasional Kepulauan Seribu (TNKpS). Sedangkan untuk data skunder didapat melalui dokumen yang belum dipublikasi adalah dalam bentuk laporan dan peraturan yang relevan dengan topik penelitian dan dokumen yang telah terpublikasi diperoleh melalui penelusuran dengan menggunakan kata kunci distribusi lamun, spesies lamun dan status konservasi lamun melalui internet. Teknik pengumpulan data dilakukan dengan Metode observasi, Focus Group Discussion (FGD), dan metode wawancara bebas. Teknik analisis data yang digunakan berupa deskriptif analisis untuk memaparkan mengenai jenis dan ciri lamun yang ada di Taman Nasional Kepulauan Seribu di Pulau Pramuka, Kepulauan Seribu Provinsi DKI Jakarta.

\section{HASIL DAN PEMBAHASAN Kualitas Perairan}

Perairan di Pulau Pramuka memiliki drajat keasaman atau $\mathrm{pH}$ berkisar antara 6-7 bersifat netral dengan salinitas rata-rata 25/1.020 per mill yang artinya setiap $1.020 \mathrm{mg}$ air terdapat 
$25 \mathrm{mg}$ garam. Air di wilayah ini memiliki rasa payau dan berwarna biru muda kehijauan karena terdapat ekosistem lamun dan merupakan air dangkal.

\section{Jenis-Jenis Lamun}

Menurut Keputusan Menteri No.200 Tahun 2004, dijelaskan bahwa lamun (seagrass) adalah tumbuhan berbunga (angiospermae) yang hidup dan tumbuh di laut dangkal, mempunyai akar, rimpang (rhizome), daun, bunga, dan buah dan berkembang biak secara generatif (penyerbukan bunga) dan vegetatif (pertumbuhan tunas).Jumlah jenis lamun di dunia adalah 60 jenis, yang terdiri atas 2 suku dan 12marga (Kuo \& McComb, 1989). Di kawasan Taman Nasional Kepulauan Seribu atau NTKpS terdapat 7 jenis lamun yaitu,Enhalus acoroides, Thalassia
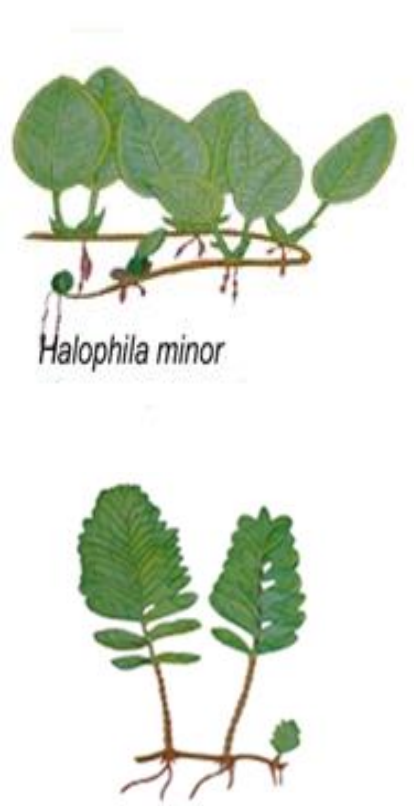

Halophila spinulosa
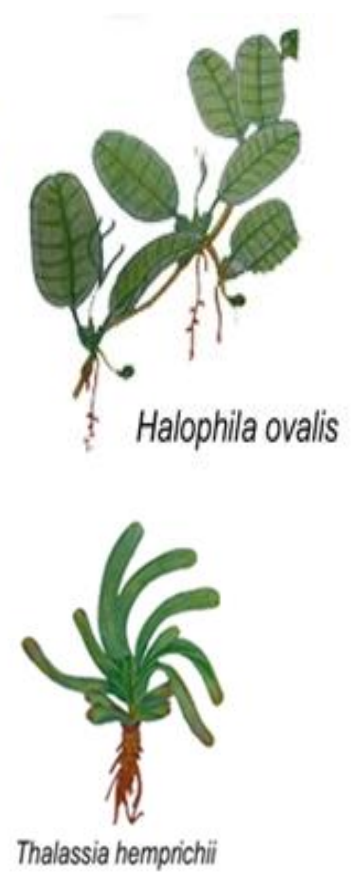

hemprichii, Cymodocea serrulata, Cymodocea rotundata, Halophila ovalis, Syringodium isoetifolium, dan Halodule uninervis (BTNKpS 2008). Dengan ciri dari masingmasing lamun yang ada di TNKpS, sebagai berikut: Famili Potamogetonaceae. Dengan jenis spesies yaitu, Cymodocea rotundata, memiliki ciri khusus, Rhizoma berbentuk silinder. Tepi daun membulat dan tumpul tidak bergerigi dan seludang daun menutup sempurna,jumlah daun 3-4, panjang daun 4-15 $\mathrm{cm}$ dan lebar 2-4 $\mathrm{mm}$, pada helai daun terdapat 7 -15 tulang daun, tiap fragmen (node) 1- 4, bunga tidak nampak dan tumbuh di zona intertidalyang merupakan zona yang dipengaruhi oleh pasang surut air laut dengan luas area yang sempit antara daerah pasang tertinggi dan surut terendah.
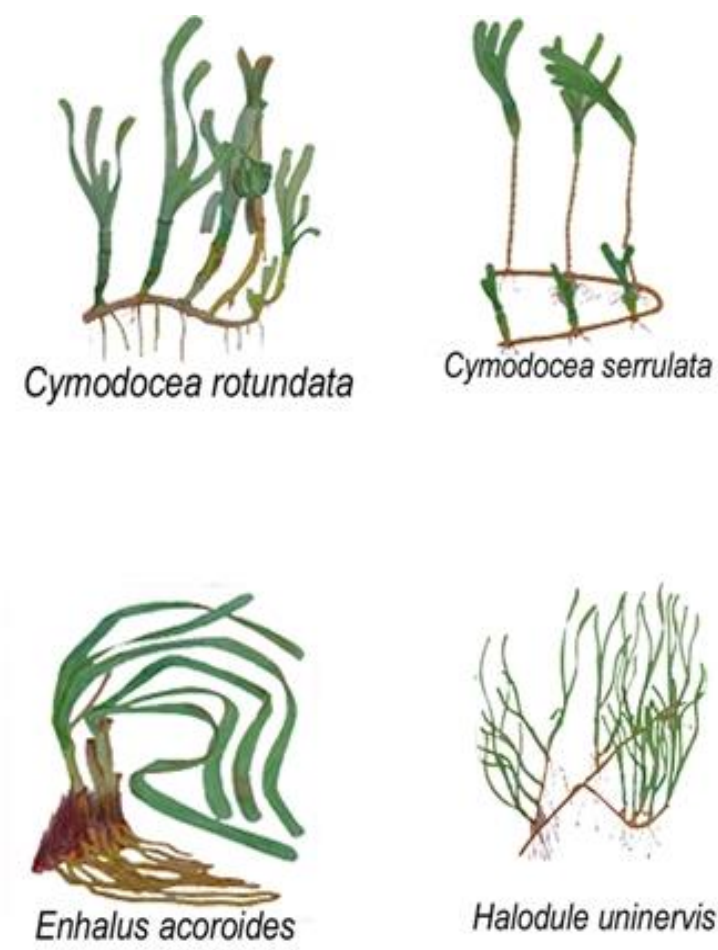

Halodule uninervis
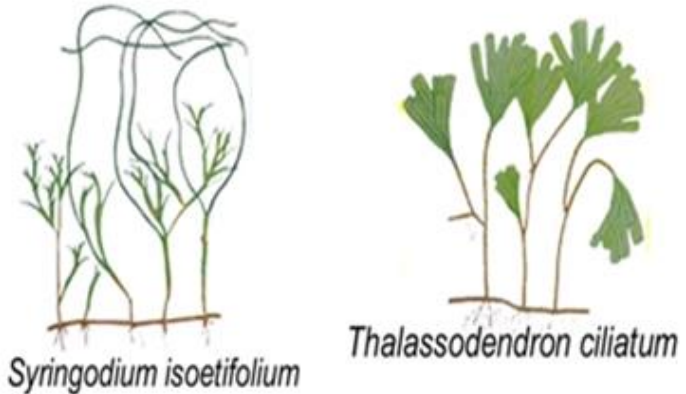
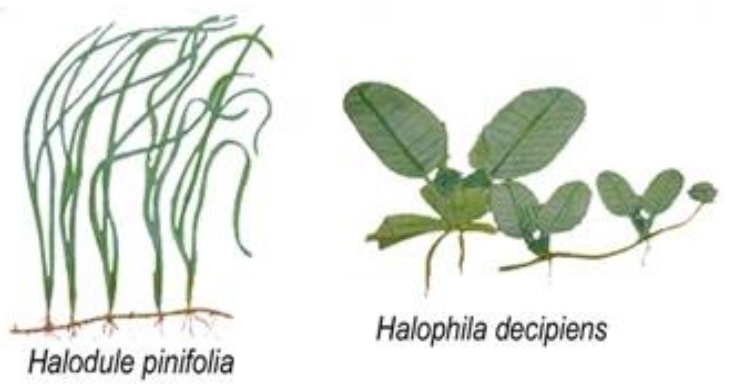

Halophila decipiens

Gambar 1. Jenis-jenis Lamun 
Cymodocea serrulate, memiliki ciri Rhizoma berbentuk silinder dan memiliki panjang 4-25 cm, dengan jumlah akar 1-3, jumlah daun 3-5 dengan panjang $4-16 \mathrm{~cm}$ dan lebar 4-6 mm, Tepi daun, bulat bergerigi, seludang daun membentuk segitiga, tidak menutup sempurna dan ditemukan di daerah intertidal.

Halodule uninervis, memiliki ciri daun pipih panjang, tapi berukuran kecil,Tulang kurang dari 13, Satu urat tengah daun jelas, Rhizome halus dengan bekas daun jelas menghitam danujung daun seperti trisula, biasanya ditemukan pada substrat berpasir dan berlumpur atau di terumbu karang.

Syringodium isoetifolium, memiliki ciri khas Rhizoma antar fragmen 1-5, memiliki daun berbentuk silindris,panjang daun $16 \mathrm{~cm}$ dengan lebar 1-3 mm, memiliki bunga jantan dan betina. Famili Hydrocharitaceae. Dengan jenis spesies, Enhalus acoroides, Ukuran panjang lebih dari 1 meter, helai daun linier (sejajar), buah berbentuk bulat, ujung daun membulat dan tumbuh pada substrat berlumpur.

Halophila ovalis,memiliki daun oval atau bulat dan panjang antara 1- $4 \mathrm{~cm}$ dan lebar $0,5-2,0 \mathrm{~cm}$,tulang daun 8 atau lebih, permukaan daun tidak berambut,seperti semanggi, berpasangan dengan tangkai pada tiap ruas dari rimpang, dan mampu tumbuh sampai kedalaman $25 \mathrm{~m}$.

Thalassia hemprichii, Mirip Cymodocea rotundata, tetapi Thalassia hemprichii memiliki rhizoma beruas-ruas dan tebal, Garis atau bercak coklat pada helaian.

Daun Rhizoma tebal sampai $5 \mathrm{~mm}$, pada umumnya panjang daun mencapai $40 \mathrm{~cm}$ dan lebar $0,4-1,0 \mathrm{~cm}$, helai daun berbentuk pita.

\section{Status Konservasi Lamun Di Taman Nasional Kepulauan Seribu}

Pengelolaan kawasan konservasi pada dasarnya menggunakan acuan rencana pengelolaan dan zonasi yang telah disusun berdasarkan Keputusan Direktur Jenderal Perlindungan Hutan dan Konservasi Alam Departemen Kehutanan Nomor SK.05/IVKK/2004. Berdasarkan Keputusan Kepala Balai Taman Nasional Kepulauan Seribu No : SK.35/BTNKpS-1/2014 Tentang Sumber Daya Alam Penting 10 (sepuluh). Sumber daya alam penting yang menjadi Target Konservasi Pada Taman Nasional Kepulauan Seribu, yakni: Terumbu Karang, Mangrove, Molusca, Penyu, Lamun, Hutan Pantai, Elang, Mamalia Laut, Ikan Ekonomis dan Burung Migran.

Untuk konservasi lamun, pada tahun 2006, telah dilakukan penanaman lamun sebagai bentuk kegiatan rehabilitasi habitat seluas $7.500 \mathrm{~m}^{2}$ oleh pihak Taman Nasional Kepulauan Seribu.

\section{Manfaat dan Fungsi Lamun}

Padang lamun di hamparan pesisir memiliki banyak manfaat yaitu :

- Produsen Primer, Lamun merupakan tumbuhan autotrofik (mengikat karbondioksida $\left(\mathrm{CO}^{2}\right)$ dan mengubahnya menjadi energi). Energi yang dihasilkan tersebut, selanjutnya dimanfaatkan oleh herbivor maupun konsumen selanjutnya. Produktivitas primer padang lamun relatif tinggi di pesisir.

- Habitat Biota Laut, Lamun menjadi tempat perlindungan, daerah asuhan, padang penggembalaan dan makanan dari berbagai jenis ikan herbivora dan ikan-ikan karang. Beberapa biota terancam punah (endangered species) seperti dugong dan penyu, memanfaatkan lamun sebagai makanan utamanya.

- Stabilisator Dasar Perairandan Penangkap Sedimen, Daun lamun yang lebat akan memperlambat aliran air yang disebabkan oleh arus dan gelombang, sehingga perairan di sekitarnya menjadi lebih tenang dan mencegah erosi pantai. Lamun memiliki rimpang dan akar yang dapat menahan dan mengikat sedimen, sehingga dapat menguatkan dan menstabilkan dasar permukaan.

- Pendaur Hara, Lamun memiliki fungsi utama dalam daur berbagai zat hara dan elemen-elemen langka (mikro nutrien) di lingkungan laut. Fosfat yang diambil oleh daun-daun lamun dapat bergerak sepanjang helai daun dan masuk ke dalam algae epifitik. Akar lamun dapat menyerap fosfat yang keluar dari daun yang membusuk yang terdapat pada celah-celah sedimen. Zat hara tersebut secara potensial dapat digunakan oleh epifit apabila mereka berada dalam medium yang miskin fosfat. 


\section{Penyebab Penurunan Komunitas Lamun}

Sebaran padang lamun global telah hilang sekitar 29\% sejak abad ke-19 (Waycott, et al., (2009). Penyebab utama hilangnya padang lamun secara global adalah penurunan kecerahan air, baik karena peningkatan kekeruhan air maupun kenaikan masukan zat hara ke perairan, adanya alih fungsi wilayah pesisir menjadi kawasan industri,reklamasi pantai, pengerukan dan penambangan pasir, serta pencemaran, pengunaan alat atau media untuk menangkap ikan yang tidak sesuai seperti racun potasium sianida dandinamit. Serta, beberapa faktor alami seperti, gelombang dan arus yang kuat, badai, gempa bumi, dan tsunami.

Seperti yang ada di bagian timur Pulau Pramuka, pada tahun 2018, disana terdapat pembangunan dermaga yang memiliki dampak terhadap ekosistem laut, salah satunya, lamun. Karena adanya pembangunan dermaga ataupun reklamasi akan memberikan dampak negative. Salah satunya, untuk menunjang pembangunan atau kelancaran proses tersebut akan menghilangkan beberapa ekosistem mangrove atau menebang mangrove dan tumbuhan pantai yang memiliki fungsi sebagai penyaring sedimen. Akibatnya Jumlah sedimen akan berlebih di daerah pesisir dan sediment yang berlebihan tersebut menyebabkan kekeruhan dan menghambat pertumbuhan serta, kondisi dari komunitas lamun.

\section{SIMPULAN}

Taman nasional kepulauan seribu memiliki 7 jenis lamun yang terdiri dari dua family yaitu family Potamogetonaceae dan Hydrocharitaceae dengan masing-masing ciri yang berbeda.Status konservasi lamun di wilayah TNKpS masih sangat terbatas yaitu hanya pada kawasan konservasi Taman Nasional Kepulauan Seribu tetapi, lamun sudah mulai diperhatikan. Melalui kegiatan rehabilitasi habitat seluas $7.500 \mathrm{~m}^{2}$ pada tahun 2006 lalu, dan akan ditingkatkan kembali guna menunjang ekosistem daerah pesisir dan ekosistem atau komunitas lamun tersebut. Lamun berfungsi sebagai tanaman penjernih airdan kondisisnya sekarang terancam akibat adanya reklamasi pelabuhan yang sedang berlangsung di pesisir Pulau Pramuka.

\section{DAFTAR PUSTAKA}

Syukur, A. (2015). Distribusi, Keragaman Jenis Lamun (Seagrass) dan Status Konservasinya di Pulau Lombok. Jurnal Biologi Tropis. Volume 15 (2), 171-182.

Lanyon, J. (1986). Seagrasses of the Great Barrier Reef. Great Barrier Reef Marine Park Authority Special Publication Series (3).

[BTNKpS] Balai Taman Nasional Kepulauan Seribu. (2008). Inventarisasi padang lamun di Taman Nasional Kepulauan Seribu. Jakarta. 44 hlm.

Apramilda, Riesna. (2011). Status Temporal Komunitas Lamun Dan Keberhasilan Transplantasi Lamun Pada Kawasan Rehabilitasi Di Pulau Pramuka Dan Harapan, Kepulauan Seribu, Provinsi DKI Jakarta[skripsi]. Departemen Manajemen Sumberdaya Perairan Fakultas Perikanan Dan Ilmu Kelautan, Institut Pertanian Bogor: Bogor.

Kementrian Lingkungan Hidup. (2004). Salinan keputusan menteri lingkungan hidup nomor 51 tentang baku mutu air laut untuk biota laut. Jakarta.

Kementrian Lingkungan Hidup. (2004). Salinan keputusan menteri lingkungan hidup nomor 200 tentang kriteria baku kerusakan dan pedoman penentuan status padang lamun. Jakarta.

Sjafrie, N. D. M., Iswari, M. Y., Suyarso, ...,Rahmat. (2017). Status Padang Lamun Indonesia 2017. Puslit Oseanografi - LIPI, Bibliografi : hlm. 23.

Anonim. (2010). Saatnya peduli ladang lamun. Jakarta: Harian Kompas.

Anonim. (2012). Informasi Taman Nasional Laut. Kementrian Kehutanan. Jakarta.

Arellano, B. J., Menguita, K., Omar, M, Jumawan, J. (2014). Comparative diversity analysis and species composition of seagrass and macroalgae along the 
intertidal zone of sarangani province, Philippines. Journal of Biodiversity and Environmental Sciences (JBES), Vol. 5, No. 4, p. 356-364.

Citra S.U. Dewi, Soedharma, D., Kawaroe, M. (2012). Komponen Fitokimia Dan Toksisitas Senyawa Bioaktif Dari Lamun Enhalus Acoroides Dan Thalassia Hemprichii Dari Pulau Pramuka, Dki Jakarta. Jurnal Teknologi Perikanan dan Kelautan. Vol. 3. No. 2. ISSN 2087-4871.

Feryatun F., Hendrarto, B., Widyorini, N. (2012). Kerapatan Dan Distribusi Lamun (Seagrass) Berdasarkan Zona Kegiatan Yang Berbeda Di Perairan Pulau Pramuka, Kepulauan Seribu. Journal Of Management Of Aquatic Resources.Volume, Nomor Halaman 1-7.

Assuyuti, Y. M., Rijaluddin, A. F., Ramadhan, F., Zikrillah, R. B. (2016). Estimasi jumlah biomassa lamun di Pulau Pramuka, Karya dan Kotok Besar, Kepulauan Seribu, Jakarta. Depik 5(2): 85-93. DOI: http://dx.doi.org/10.13170/depik.5.2.4914.

Pratiwi R. (2010). Asosiasi Krustasea di ekosistem padang lamun Perairan Teluk Lampung. Ilmu Kelautan, Vol. 15(2); 6676.
Maabuat PV, Sampekalo J, Simbala HEI. (2012). Keanekaragaman lamun di pesisir Pantai Molas, Kecamatan Bunaken, Kota Manado. J. Bios Logos. Vol 2(1): 20 - 27.

Anonim. (2018). Kuisioner Osenografi Fieldtrip Angkatan 2017. Universitas Negeri Jakarta : Jakarta.

Anonim. (2018). Kuisioner Biogeografi Fieldtrip Angkatan 2017. Universitas Negeri Jakarta : Jakarta.

Suraji, Suraji., Rasyid, Nilfa.,Jannah, A. R., Handayani, S. N. (2015). Profil Kawasan Konservasi Provinsi Dki Jakarta. Direktorat Konservasi Kawasan dan Jenis Ikan, Direktorat Jenderal Kelautan, Pesisir dan Pulau-Pulau Kecil Kementerian Kelautan dan Perikanan. Diakses melalui: http://kkji.kp3k.kkp.go.id.

Undang-Undang Republik Indonesia Nomor 27 Tahun 2007 Tentang Pengelolaan Wilayah Pesisir Dan Pulau-Pulau Kecil.

Peraturan Menteri Kelautan Dan Perikanan Republik Indonesia Nomor Per.16/Men/2008 Tentang Perencanaan Pengelolaan Wilayah Pesisir Dan PulauPulau Kecil. 